\title{
ФОРМИРОВАНИЕ ВЫБОРКИ ДЛЯ ОПРОСОВ ПРЕДПРИЯТИЙ: ЛУЧШИЕ ПРАКТИКИ ЭКОНОМИЧЕСКИХ ПОДРАЗДЕЛЕНИЙ ТЕРРИТОРИАЛЬНЫХ УЧРЕЖДЕНИЙ БАНКА РОССИИ В РЕГИОНАЛЬНОМ ЭКОНОМИЧЕСКОМ АНАЛИЗЕ
}

\author{
(c) 2019 Рахматулин Роман Наильевич \\ начальник экономического отдела \\ Отделение по Омской области Сибирского главного управления \\ Центрального банка Российской Федерации, Россия, Омск \\ E-mail: RakhmatulinRN@cbr.ru \\ (C) 2019 Михалев Олег Владимирович \\ доктор экономических наук, главный экономист \\ Отделение по Омской области Сибирского главного управления \\ Центрального банка Российской Федерации, Россия, Омск \\ E-mail: MikhalevOV@cbr.ru
}

В статье рассмотрены вопросы организации конъюнктурных обследований бизнеса, особое внимание уделено проблемам формирования региональных выборок российских предприятий. На примере мониторинга предприятий, проводимого Банком России, выделены лучшие практики сохранения и привлечения респондентов к участию в опросах. Показано, что их использование, учитывающее региональные особенности и накопленный опыт, способно привести к значимым результатам.

Ключевые слова: региональная экономика, экономический анализ, мониторинг предприятий, лучшие практики, формирование выборки, Банк России

Введение: опросы предприятий как источник информации для экономического анализа

Для формирования базы экономического анализа, помимо официальной статистики, широкое распространение получили конъюнктурные обследования бизнес-среды, основанные на прямых опросах компаний независимыми организациями. Релевантность использования качественной информации конъюнктурных обследований в анализе экономической динамики развитых стран основана, прежде всего, на современные концептуальных предпосылках, объясняющих взаимосвязь деловых циклов с оценками и ожиданиями непосредственных участников рынка [3]. Этим обусловлен высокий спрос на результаты таких обследований, лежащих в основе формирования системы опережающих индикаторов социально-экономических процессов. Например, обзор международного опыта обследований бизнес-климата (на при-

мере малого и среднего предпринимательства) можно найти в работе И.С. Лолы (НИУ ВШЭ) [5], российская практика эмпирических обследований отечественных компаний подробно представлена в трудах Т.Г. Долгопятовой (ГУ ВШЭ), в частности, в работе [2].

Центральные банки развитых стран, будучи одними из первых активных пользователей результатов бизнес-обследований в рамках проведения монетарной политики, довольно быстро пришли к необходимости самостоятельно опрашивать предприятия, что позволило им обладать первичной, оперативной и несмещенной информацией, формируя ее под свои целевые установки. Пионерными исследованиями коммерческого сектора известен Банк Франции, ведущий их со времен Наполеона; также успешно и регулярно взаимодействуют с бизнес-сообществом развитых стран ФРС США, Банк Италии, Банк Ирландии, Банк Израиля,

\footnotetext{
"Статья подготовлена в рамках специализации опорного территориального учреждения Банка России - Отделения по Омской области Сибирского главного управления Центрального банка Российской Федерации - по направлению «Внедрение лучших практик регионального экономического анализа».

Авторы выражают искреннюю благодарность С.А. Донец, А.М. Гришину и И.Л. Даниловой за ценные замечания, а также всем сотрудникам Банка России, принявшим активное участие в сборе и подготовке информации о лучших практиках по теме «Сохранение и увеличение выборки предприятий - участников мониторинга Банка России для обеспечения ее репрезентативности», и сожалеют, что рамки журнальной статьи не позволяют перечислить всех поименно.
} 
Банк Турции, Банк Японии и другие [9, 11]. В новом веке на постсоветском пространстве активно внедряют результаты собственных опросов предприятий в практику денежно-кредитного регулирования национальные банки Республики Беларусь, Казахстана, Армении, Таджикистана, Украины, Азербайджана.

Банк России, в 1997 году разработавший с участием зарубежных специалистов проект «Мониторинг предприятий» (далее - МП), распространил его на всю территорию страны в 2000 году, регулярно опрашивая с тех пор от 8000 до 16000 российских предприятий во всех регионах (более подробно о проекте и результатах его реализации можно найти в многочисленных работах сотрудников Банка России, например, [4, 7, 10]).

Основной проблемой, с которой сталкивается Банк России на всем периоде проведения МП, было и остается поддержание выборки на уровне, необходимом для ее репрезентативности в силу отсутствия законодательной основы для предоставления ему нефинансовыми организациями информации, включенной в опросные анкеты.

МП Банком России: проблема формирования выборки

Проблема участия в добровольных обследованиях экономических субъектов решается 1) взаимовыгодным обменом информацией, либо 2) ее «покупкой». Например, опыт Банка Франции показывает, что заинтересованность предприятий участвовать в МП «куплена» получением ими рейтинговых оценок, которые выставляются регулятором на основе информации, полученной в ходе МП, и служат необходимым условием для получения коммерческих ссуд в кредитных организациях страны [12]. Относительно короткая история МП в России пока не позволяет широко использовать подобный опыт; отечественные респонденты, участвуя в МП, получают аналитические продукты Банка России: сводные материалы, обобщающие результаты опросов по региональному и отраслевому признаку, и индивидуальные материалы с относительными показателями этого участника.

В работах сотрудников Банка России, связанных с МП, в основном, представлены результаты регионального экономического анализа, полученные на данных МП. Проблема формирования выборки отражена в постановочном плане, a ее решения показаны в области «обратной связи» с предприятиями, по сути, описаны стандартизированные процедуры, предопределен- ные централизованно (стандартный пакет возвратной сводной аналитической информации). Лучшие практики, которые можно почерпнуть из этих работ, также связаны с совершенствованием аналитических продуктов, их индивидуализацией под конкретные запросы отдельных предприятий. В то же время, если подготовка таких материалов не автоматизирована, индивидуальный анализ потребует отвлечения существенных ресурсов.

Более того, представления о том, что выходная аналитическая информация может представлять постоянный и достаточно большой интерес для участника обследований, тем более, если эти обследования российского бизнеса регулярны и аналитика типична, на взгляд авторов, весьма сомнительны. Это мнение находит свое подтверждение в специальных исследованиях, направленных на выявление удовлетворенности результатами опросов их участников как пользователей информационно-аналитических материалов. В работе [6] априори предполагалось, что чем убедительнее доводы и аргументы организатора в его работе с предприятиями, привлекаемыми к сотрудничеству, и чем качественнее информация, возвращаемая респондентам, тем выше их отклик, или уровень возврата анкет в опросах, носящих добровольный характер участия. Но там же указано, что даже в Великобритании лишь пятая часть участников опросов Конфедерации британской промышленности регулярно использовали выходную аналитику в целях своего бизнес-планирования.

Результаты российских исследований [6] также показали снижающийся интерес участников к итогам опросов как источникам экономической информации с его понятными всплесками во время дефолта 1998 года и кризиса 2008 года, когда оперативности официальной статистики стало недостаточно для принятия бизнесрешений. Не менее явно отреагировала полезность возвращаемых респондентам материалов на кардинальное изменение формы их представления. Другими словами, стандартизированные аналитические продукты в периоды спокойной конъюнктуры не имеют в глазах респондентов ценности, достаточной для поддержания заинтересованности в регулярном участии в опросах.

Таким образом, основная проблема формирования выборки в бизнес-обследованиях связана с падением отклика предприятий в процессе их мониторинга, в результате чего снижается репрезентативность региональных выборок. Соответственно, задача настоящего исследова- 
ния - определить факторы, влияющие на объем и структуру региональной выборки в процессе МП.

\section{Гипотеза исследования и исходные данные}

Объем региональной выборки $\left(n_{i}\right)$ зависит от количества зарегистрированных хозяйствующих субъектов на территории региона $i$ - генеральной совокупности $\left(N_{i}\right)$.

Гипотеза не находит своего подтверждения по результатам корреляционного анализа. Уровень возможной взаимосвязи между объемом региональной выборки (количество наблюдений - регионов - от 78 до 81 в 2000-2016 гг.) и числом субъектов в статистическом регистре (авторы понимают, что нужно учитывать только действующие предприятия, но исходят из того, что доля недействующих примерно одинакова для разных регионов и составляет порядка 50\%) статистически незначим, в том числе при последовательном исключении «выбросов» (г. Москвы, Московской области, г. Санкт-Петербурга, Свердловской, Новосибирской областей, Краснодарского края и т.д.; максимальное значение коэффициента корреляции составило лишь +0,407 в 2010 году при отбрасывании 10\% наблюдений с самым высоким $N_{i}$ ). В то же время, между размером региональной экономики $\left(N_{i}\right)$ и долей обследуемых предприятий $\left(d n_{i}=n_{i} / N_{i}\right)$ наблюдается обратная зависимость вида $\left(d n_{i}=a / N_{i}^{k}\right)$, где $k$ примерно равно 1 , с довольно высоким уровнем детерминации $\left(\mathrm{R}^{2}=0,702\right)$. Это говорит о том, что чем больше экономика региона, тем ниже возможности формирования выборки, пропорциональной ее масштабу.

Данный вывод согласуется с теорией социологии, из которой хорошо известна нелинейная зависимость между требуемым для репрезентативности объемом выборки и генеральной совокупностью при прочих равных условиях (уровне точности оценивания, риска, допустимой ошибке) [1].

Моделирование процесса формирования выборки

В качестве альтернативной гипотезы полагаем, что ni зависит от совокупности факторов, и, учитывая динамику процесса, запишем простую модель:

$$
n_{i, t}=n_{i, t-1}-\alpha n_{i, t-1}+\beta N_{i, t}^{0}+e_{t}
$$

где $\alpha$ - коэффициент выбытия, показывает, как уменьшается выборка в условиях минимальных усилий организатора по ее сохранению; в общем случае также зависит от времени (пери- ода) $t$ и региона $i$ :

$$
\alpha_{i, t}=\alpha_{0}-f\left(k_{i, t} ; p_{\alpha, i}\right)
$$

$\beta$ - коэффициент привлечения, показывает вероятность согласия предприятия участвовать в опросах в результате взаимодействия с ним организатора:

$$
\beta_{i, t}=\varphi\left(k_{i, t} ; p_{\beta, i}\right)
$$

$N^{0}$ - число потенциальных респондентов, с которыми была проведена работа по привлечению к участию в МП; в общем случае зависит от числа сотрудников, взаимодействующих с предприятиями $\left(k_{i, t}\right)$, или, точнее, их рабочего времени (ПШЕ), организации работ и ограничено сверху

$$
N_{i, t}^{\max }=N_{i}-\sum_{\tau=1}^{t-1} N_{i, \tau}^{0}
$$

$p_{\alpha}, p_{\beta}-$ производительность труда сотрудников организатора, соответственно, по сохранению участников МП и привлечению новых.

Последние параметры модели, в условиях добровольного участия в опросах, связаны не только с интенсивностью труда, но и с применением более совершенных техник, методик и способов привлечения предприятий к опросам и последующего удержания их в числе участников МП, то есть тех инноваций во взаимодействии с предприятиями, которые позволяют нарастить выборку и которые, для краткости, далее будем именовать лучшими практиками (далее ЛП). При этом, модель учитывает, что в случае минимизации усилий на поддержание выборки и ограниченного применения стандартных (массовых), давно используемых ЛП (например, «холодная» рассылка), выборка сокращается за счет естественного выбытия предприятий, для которых выгода в виде информационноаналитических продуктов Банка России менее значима, чем затраты рабочего времени на участие в опросах.

Результаты расиетов, интерпретация и выводы

В качестве исходных данных в декабре 2018 года были собраны, обработаны и выявлены 245 ЛП, используемых 72 ТУ Банка России в период 1999-2018 гг.

В результате проведенных расчетов модели (1) не удалось найти статистически значимой взаимосвязи между показателями выборки $\left(n_{i, t}\right.$,

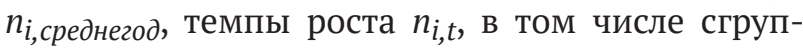


пированные) и гипотетическими факторами ее формирования (общее число ЛП, число ЛП с учетом их результативности, интенсивность применения, период применения) во всех периодах 2000-2018 гг. Единственным относительно работающим фактором модели может быть признан количественный показатель $k_{i, t}$ (ПШЕ), для которого удалось выделить нелинейную (логарифмическую) связь с регионами, сгруппированными по объему выборки (при этом предельная «полезность» обнуляется с 5-й ПШЕ). Но этот фактор способен объяснить не более $15 \%$ (коэффициент детерминации) вариации региональных выборок до 2016 года.

Тем не менее, отсутствие искомых зависимостей позволяет авторам сделать следующие выводы.

1. Формирование выборки в большой степени зависит от качественного фактора (производительности труда), как показало проведенное исследование, а ее зависимость от количественного фактора (числа специалистов, занятых МП) носит нелинейный характер; соответственно, для роста выборки необходимо использовать интенсивные, а не экстенсивные методы.

2. Производительность труда напрямую не зависит от количественных показателей применения ЛП, но, на взгляд авторов, вероятно определяется спецификой специалистов, их особыми способностями к взаимодействию с предприятиями (способностями вовлечь), которые, помимо природных данных субъекта, растут с ростом опыта работы с предприятиями, но сложно поддаются квантификации.

3. Отсутствие выявленных закономерностей формирования региональных выборок, то есть их общности, можно интерпретировать как преобладание региональных особенностей, когда аналогичные ЛП имеют совершенное разные отклики и противоположную результативность в разных регионах в равных условиях (это предположение косвенно подтверждается более высокой корреляцией внутри регионов одного федерального округа (ГУ) по сравнению с корреляцией по всем регионам России); соответственно, для роста выборки в конкретном регионе стоит внедрять новую ЛП только после ее экспертизы (или апробации) опытным региональным специалистом по МП, знакомым с местной спецификой бизнес-среды.

4. В целом для роста выборки необходим инновационный подход, предусматривающий применение постоянно меняющейся системы ЛП, а для ее сохранения необходимы относи- тельно стабильные условия участия: сроки, периодичность и виды опросов, постоянный состав вопросов анкет и т.п. Как показывает практика, иногда эти условия находятся в противоречии, что несколько затрудняет задачу формирования выборки.

Полагаем, что дальнейший мониторинг заглавной проблемы позволит авторам собрать новые данные, доработать математическую модель и получить количественные результаты взаимосвязи ЛП и объема выборки.

\section{Обзор ЛП формирования выборки}

Отсутствие прямого количественного подтверждения гипотезы о существовании некого набора ЛП, позволяющего существенно повысить производительность труда специалистов МП в их взаимодействии с предприятиями, по мнению авторов, не является достаточным основанием для игнорирования идеи их использования в практике регулярных бизнесобследований.

В истории МП, проводимого Банком России, было по меньшей мере два периода, когда ослабление интенсивности применения ЛП приводило к снижению российской выборки: в 2004 году это было связано с пересмотром основных целей проведения МП, переносом акцентов на функциональную составляющую выборки для решения задач банковского надзора; в 20132017 гг.- с реорганизацией территориальной структуры Банка России и большего внимания официальной статистике и анализу финансовых рынков. В этот период сокращение выборки достигло критических 25\%, а число специалистов, занимающихся региональным экономическим анализом и МП в Банке России, по оценкам авторов, снизилось на 20\% (сокращение региональных выборок в 2013-2017 гг. выходило за рамки стандартной логистической кривой «жизненного цикла» и, следовательно, было обусловлено переориентацией специалистов на решение новых задач вне проекта МП, постепенной утратой опыта работы с предприятиями и опытных кадров). Последующее возобновление роста (прекращение спада) по времени совпадает с периодами активизации применения ЛП, что заметно на графике их концентрацией. Именно в эти периоды были найдены новые методы, позволившие сохранить и нарастить выборку, а также модернизированы ЛП начальных этапов МП.

Для выделения типичных практик и возможности их классификации авторами была проведена предварительная работа по уточнению и декомпозиции 245 первичных записей. В 
результате число практик (детализированных записей) возросло до 440. В ходе дальнейшей обработки и анализа записей было выявлено и кодифицировано:

- по направлению «привлечение новых предприятий к участию в МП» 6 типов практик («прямое взаимодействие с предприятиями», «взаимодействие с привлечением региональных и муниципальных органов исполнительной власти (РОИВ)», «взаимодействие через общественные организации», «взаимодействие с финансовыми (кредитными) организациями», «участие в массовых мероприятиях», «организационноуправленческие практики») и 10 форм («холодная рассылка», «индивидуальная коммуникация», «массовая коммуникация», «содействие», «нормативное оформление отношений», «неформальные контакты», «информационные и аналитические материалы», «формирование списка», «план (карта целей)», «обмен опытом»);

- по направлению «сохранение участия предприятий в МП» 3 типа практик («прямое взаимодействие с предприятиями», «взаимодействие с привлечением РОИВ», «организационно-управленческие практики») и 4 формы («индивидуальная коммуникация», «содействие», «неформальные контакты», «информационные и аналитические материалы»).

В рамках сбора ЛП предлагалось провести самооценку их результативности показателям отклика респондентов. В результате была скомпонована средняя экспертная оценка для типичных ЛП, позволяющая, с известной долей вероятности, ранжировать их по успешности возможного применения. Кроме того, в результате контент-анализа собранного материала были выявлены те дополнительные факторы, которые позволили заметно повысить результативность стандартных (обычных) практик. Именно они (в дальнейшем именуемы ЛП) позволили уточнить содержание термина ЛП применительно к заглавной теме: это не определенный тип и форма используемых практик, а те особенности их применения, или дополнительные мероприятия, поднимающие результативность типовых форм до максимального уровня внутри этого класса.

Всего было выявлено 40 подобных ЛП по направлению «привлечение новых предприятий к участию в МП» и 15 ЛП по направлению «сохранение участия предприятий в МП», которые представлены в таблице (приложение).

Как видим, наибольшей результативностью среди типовых практик привлечения новых предприятий к МП, по мнению экспертного со- общества, в роли которого выступили непосредственно специалисты Банка России, имеющие обширный опыт взаимодействия с предприятиями, в среднем обладают те, которые подкреплены содействием региональных и муниципальных органов исполнительной власти. Это обусловлено признанным за ними административным ресурсом, который особенно заметен в малых регионах. Среди этих практик максимальный отклик имеют массовые совещания, «круглые столы», рабочие встречи, организованные и проводимые совместно с местной властью, а также закрепление обязанности участвовать в МП нормативным или договорным образом. Коммуникационные сессии, организованные исключительно ТУ, также отличаются высокой результативностью, особенно, если они связаны с целевыми группами предприятий, или на них рассматриваются узкоспециальные вопросы. Еще одной результативной формой привлечения к МП, но уже в разделе организационноуправленческих практик, является установление плановых заданий руководству ТУ, закрепленных в годовой карте целей и задач.

В то же время среди практик, направленных на сохранение участия предприятий в МП, лидерство типичных взаимодействий с органами власти не столь заметно, как и число таких ЛП. Прямые встречи с руководством участников, а также неформальные контакты заслуживают не меньшего внимания, если стоит задача стабилизации выборочной совокупности. В целом, разнообразие ЛП больше представлено в вопросе привлечения новых предприятий к участию в МП, чем в вопросе сохранения существующих, что, на наш взгляд, свидетельствует о большей сложности последней задачи. Не случайно восстановление выборки за счет возобновления участия предприятий, ранее прекративших заполнять анкеты оп субъективным причинам, считается на порядок сложнее, чем привлечение новых, ранее не участвующих респондентов.

\section{Направления дальнейших исследований}

Анализ ЛП для формирования региональных выборок несколько отодвинул на задний план проблему формирования репрезентативной выборки в целом по России. В МП последняя складывается путем агрегирования всех региональных выборок ТУ Банка России, а проблемы в ее репрезентативности связаны с непропорциональностью объемов региональных выборок структуре генеральной совокупности - национальной экономике в региональном разрезе (см. Гипотеза исследования и исходные данные). 
Путем несложных математических выкладок можно показать, что необходимыми условиями репрезентативности российской выборки по отраслевому признаку будут 1) репрезентативность российской выборки по региональному признаку и 2) репрезентативность каждой региональной выборки по отраслевому признаку. Одним из возможных решений является, на взгляд авторов, процедура взвешивания.

Остается открытым и вопрос о необходимости «взвешивания» оценок предприятий при формировании агрегированных (сводных) данных: если на вопросы, имеющие количественные аналоги (например, «как изменился объем производства, заказов?») существуют объективные причины введения весов, то для качественных вопросов (например, «как изменилась экономическая конъюнктура, спрос?») оба подхода - учитывать или не учитывать масштабы респондентов - имеют равные основания для критики. Крупный респондент, точнее, исполнитель, отвечающий на вопросы анкет, далеко не всегда лучше знает текущую конъюнктуру конкретного рынка, нежели респондент от малого предприятия, зачастую являющийся собственником бизнеса, руководителем и профессиональным специалистом в одном лице.

Заметим, что для учета весов (как в случае проблемы репрезентативности российской вы- борки в целом, так и в случае агрегирования данных разных по масштабу респондентов) существуют различные методы. Введение весов возможно на этапе распространения данных выборочных опросов на генеральную совокупность, так и на этапе расчета выборки, когда учитывается структура генеральной совокупности по этому признаку (см. например [8]).

В целом, вопросы формирования репрезентативной выборки не увязаны строго с ее количественным ростом. В этом ключе заслуживает внимания стратегия одного из сибирских ТУ Банка России, которое основной задачей взаимодействия с предприятиями избрало именно репрезентативность выборки, а не ее объем. Изначально довольно значительное количество участников МП в регионе позволило провести качественный отбор респондентов, которых необходимо сохранить после ликвидации сети структурных подразделений, с учетом положенных в основу репрезентативности признаков. Однако, не стоит забывать, что в любом случае рост количества предприятий, участвующих в опросах, повышает точность и разнообразие оценок, расширяет возможности и горизонты исследования, подчас открывая исследователю новое направление в региональном экономическом анализе.

\section{Библиографический список}

1. Добреньков В.И. Методы социологического исследования: учебник / В.И. Добреньков, А.И. Кравченко.- М.: ИНФРА-М, 2018. - 768 с.

2. Долгопятова Т.Г. Эмпирические обследования предприятий: методы и практика // Экономический журнал ВШЭ, 2008. - № 4.- С. 543-572.

3. Китрар Л.А., Остапкович Г.В. Проблемы измерения деловых циклов: развитие концептуальных конструкций и основных параметров наблюдения // Вопросы статистики, 2013. - № 4.- с. 22-27.

4. Крыксин Г.В. Экономика региона: проблемы и перспективы развития // Деньги и кредит, 2002, № 11.c. 32-36.

5. Лола И.С. Международный опыт статистического измерения делового климата малого бизнеса // Вопросы статистики, 2015.- № 3.- с. 71-80.

6. Пугачева М.В., Цухло С.В. Дают ли бизнес-обследования полезную информацию украинским и российским респондентам? // Вопросы статистики, 2012.- № 11.- с. 12-20.

7. Рудько-Силиванов В.В., Савалей В.В. Финансовая экономика Дальнего Востока.- Владивосток: Изд-во ТГЭУ, 2010-156 c.

8. Степанов С.В. Отбор хозяйствующих субъектов с вероятностью, пропорциональной их размеру // Вопросы статистики, 2011.- № 11.- с. 32-44.

9. Степанов Ю.В., Гришин А.М., Марьясин М.Ш., Лисанский А. В. Пути совершенствования анализа и прогнозирования общеэкономических процессов в Банке России// Деньги и кредит, 1997, № 3.- с. 6-17.

10. Степанов Ю.В., Гришин А.М., Моргачева И.А., Залунина Л.В., Данилова И.Л. Об организации мониторинга предприятий в системе центрального банка // Деньги и кредит, 1999, № 10.- c. 28-39.

11. Степанов Ю.В., Савинская Н.А., Гришин А. М., Никитин Г.Г., Моргачева И. А. Мониторинг предприятий в центральном банке // Деньги и кредит, 1997, № 8.- с. 9-22.

12. Харитонова Е.Э. Рейтинги предприятий, присваиваемые Банком Франции // Деньги и кредит, 2015, № 3.c. 64-68. 


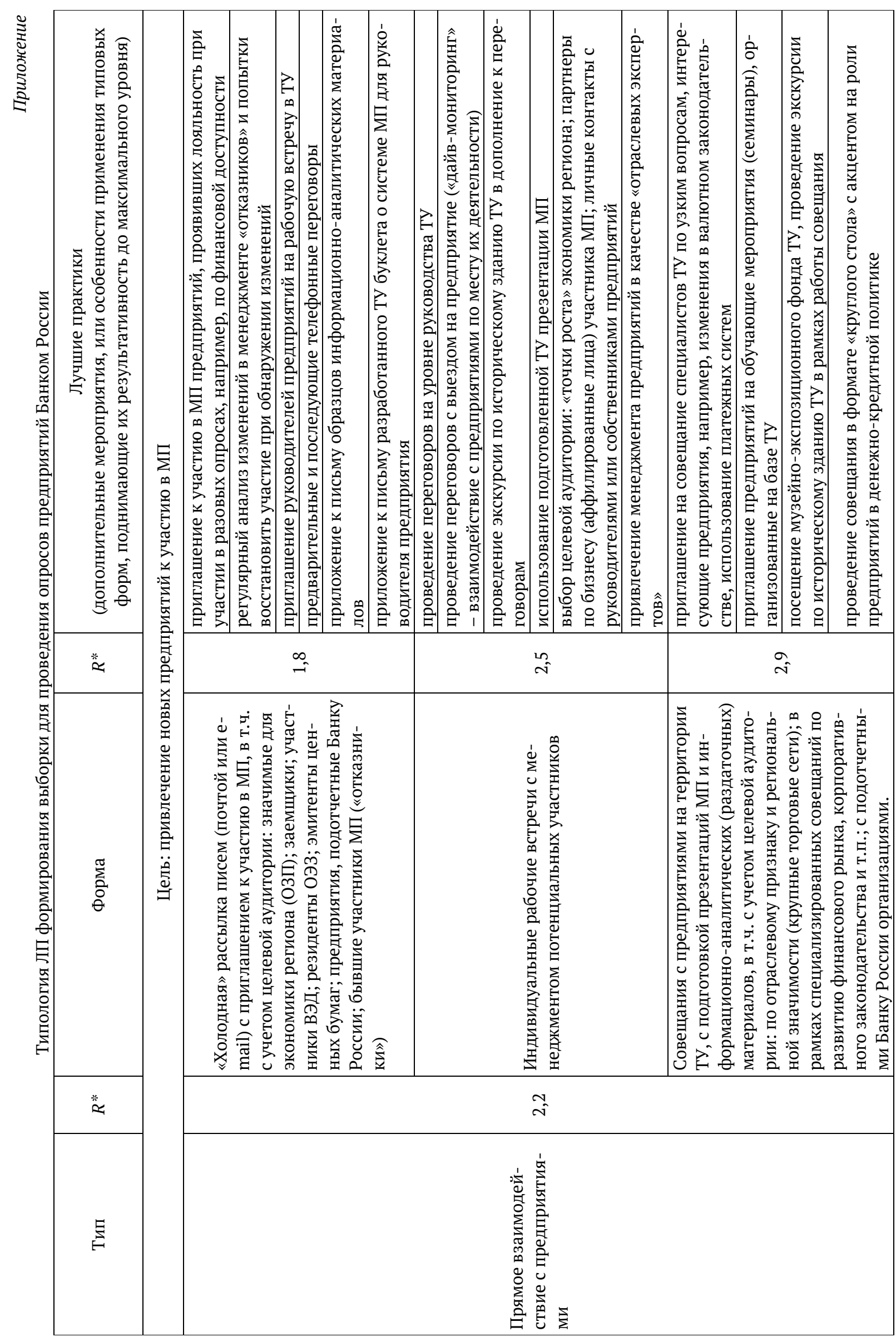




\begin{tabular}{|c|c|c|c|c|c|c|c|c|c|c|c|c|c|c|}
\hline 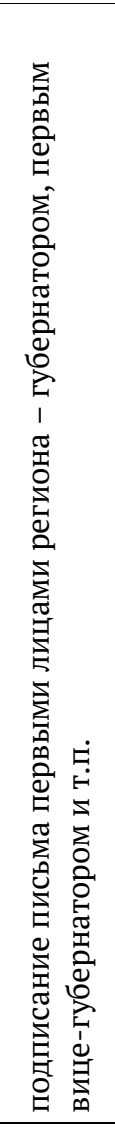 & 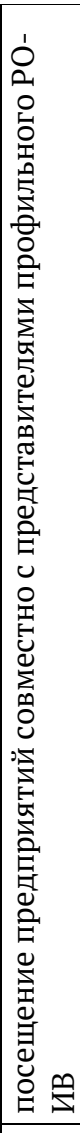 & 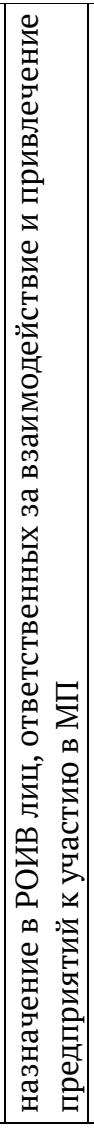 & 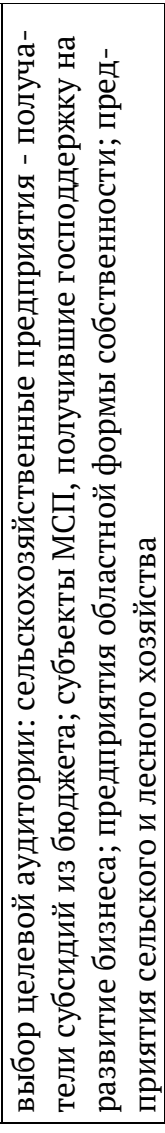 & 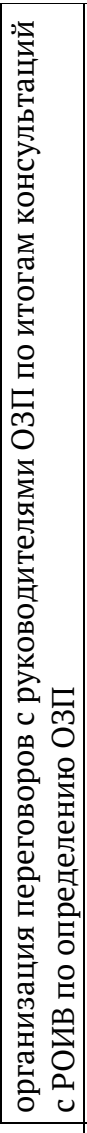 & 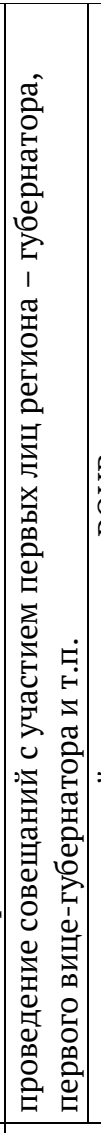 & 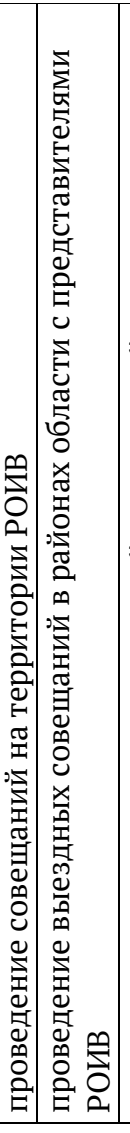 & 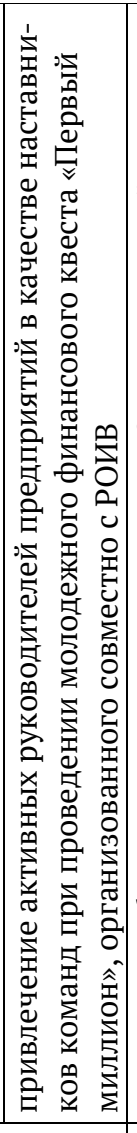 & 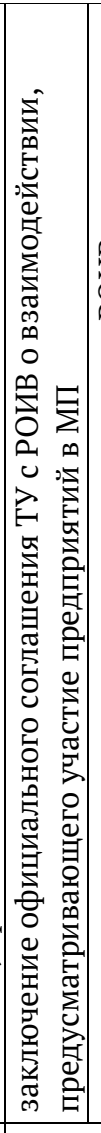 & 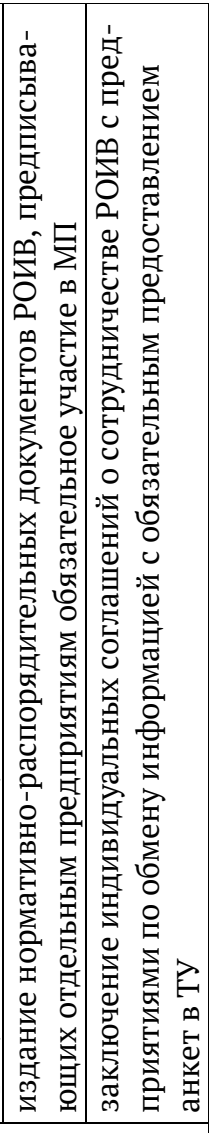 & 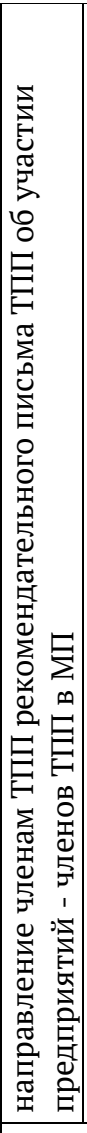 & 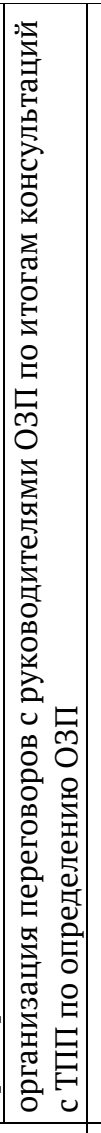 & 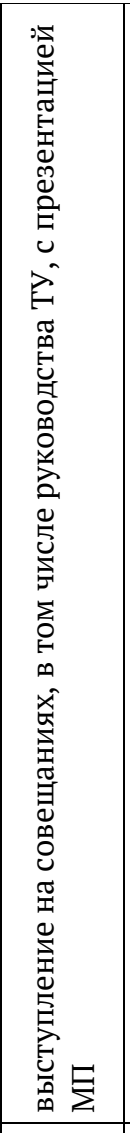 & 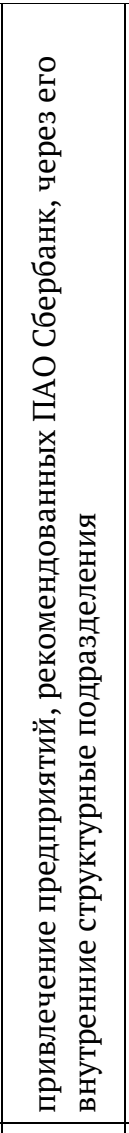 & 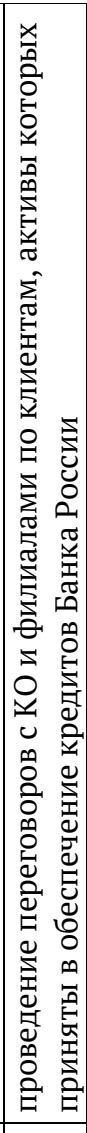 \\
\hline$\hat{i}$ & & & $\stackrel{m}{i}$ & & & $\dot{m}^{-}$ & & in & & 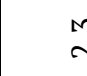 & vi & $\stackrel{\text { un }}{\mathrm{v}}$ & $\stackrel{m}{i}$ & $\vec{a}$ \\
\hline 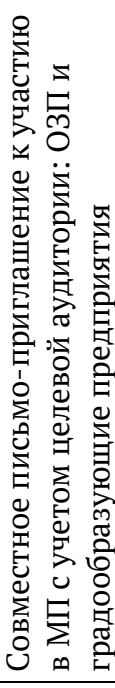 & & & 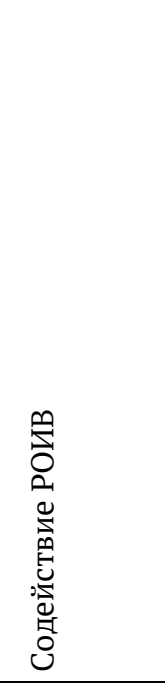 & & & 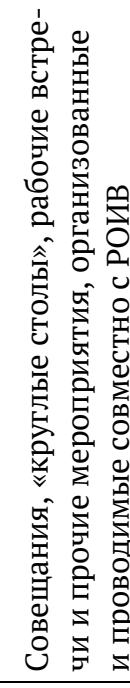 & & & 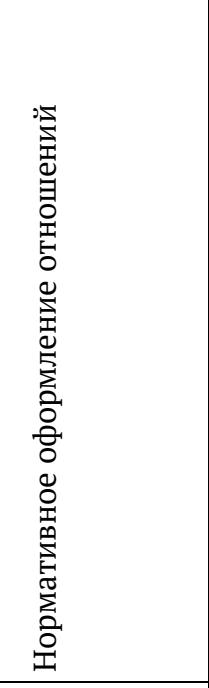 & 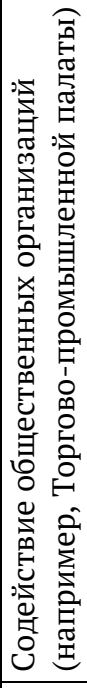 & 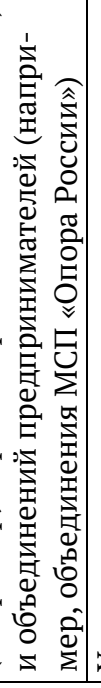 & 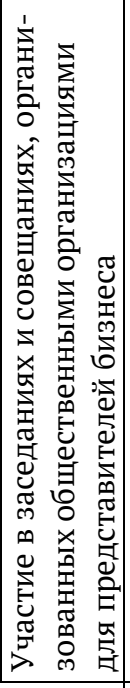 & 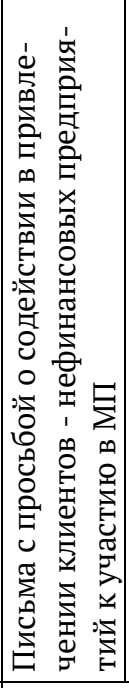 & 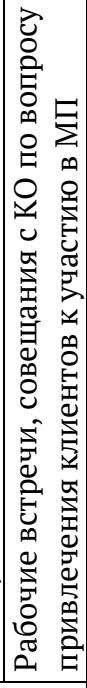 \\
\hline \multicolumn{10}{|c|}{$\hat{\mathrm{o}}$} & \multicolumn{3}{|c|}{$\stackrel{H}{i}$} & \multicolumn{2}{|l|}{$\tilde{\overbrace{}}$} \\
\hline \multicolumn{10}{|c|}{ 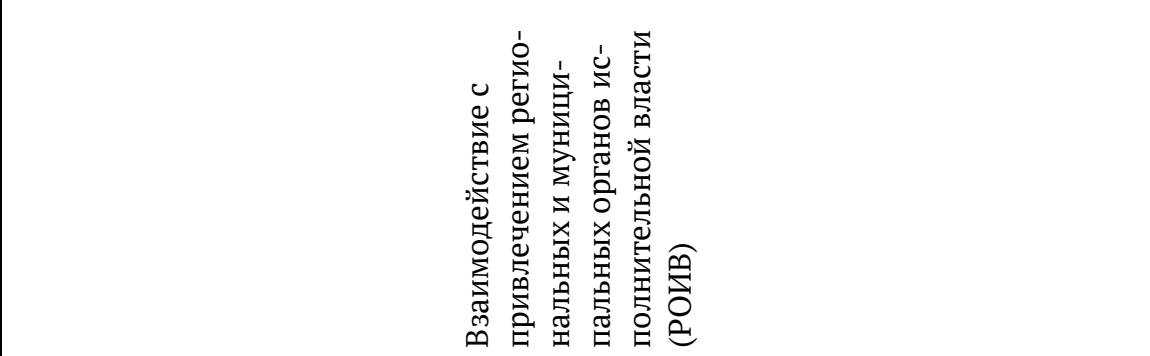 } & \multicolumn{3}{|c|}{ 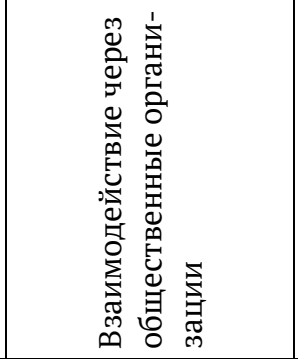 } & \multicolumn{2}{|c|}{ 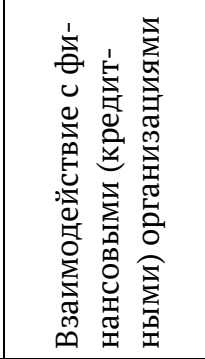 } \\
\hline
\end{tabular}




\begin{tabular}{|c|c|c|c|c|c|c|c|c|c|c|c|c|c|}
\hline 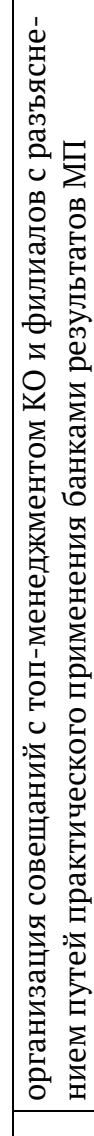 & & ' & 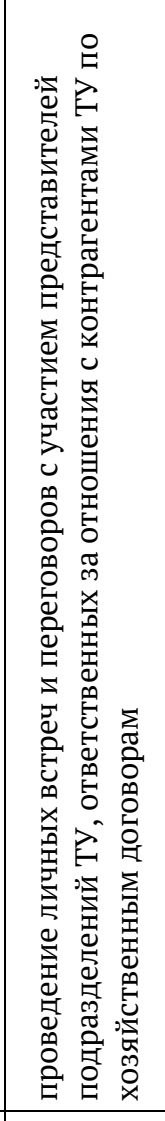 & 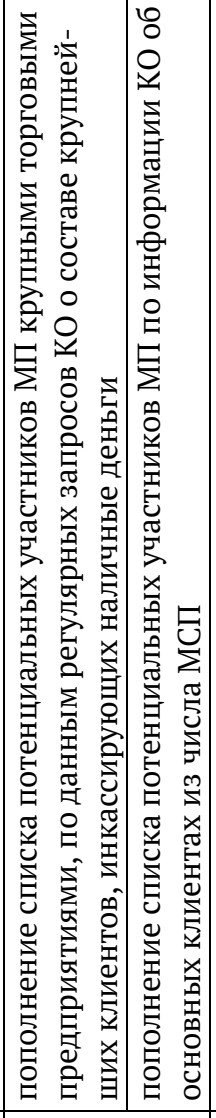 & 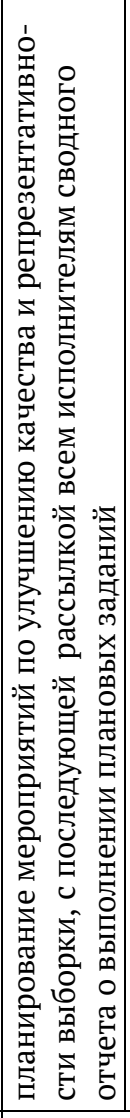 & 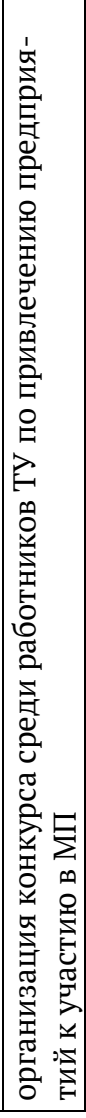 & 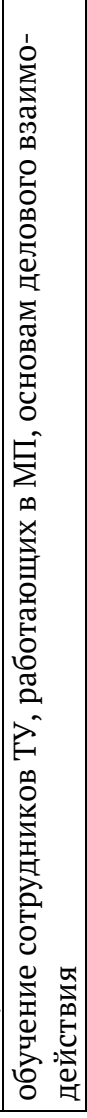 & 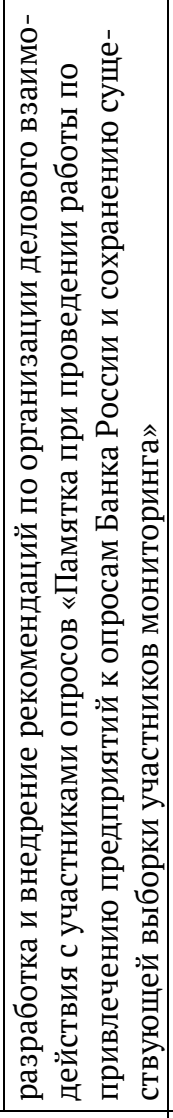 & 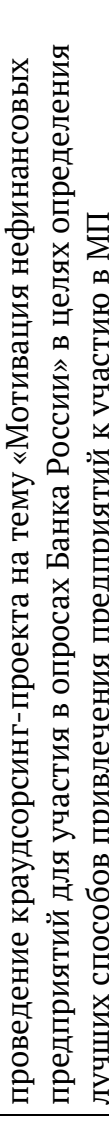 & 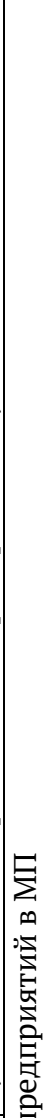 & 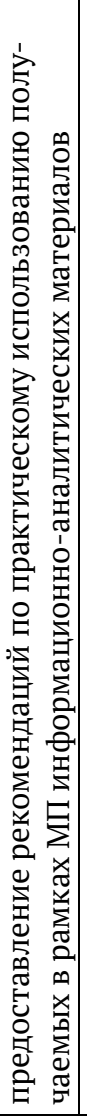 & 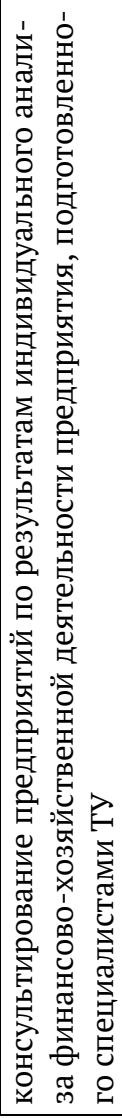 & 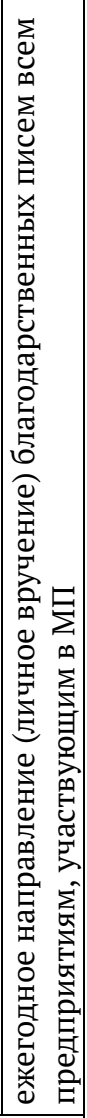 \\
\hline & $\stackrel{n}{\rightarrow}$ & 馬 & $\hat{i}$ & î & & & is & & 告 & 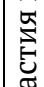 & & $\vec{i}$ & \\
\hline & 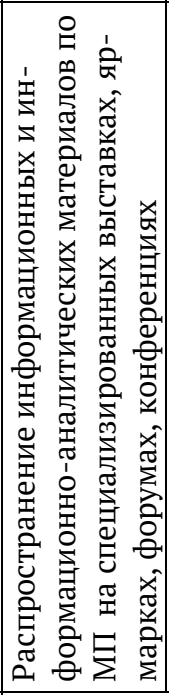 & 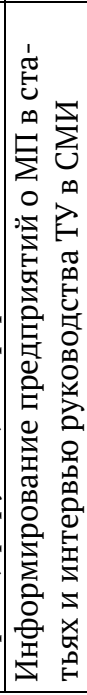 & 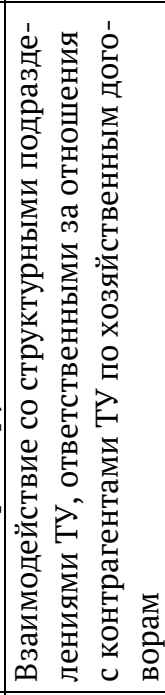 & 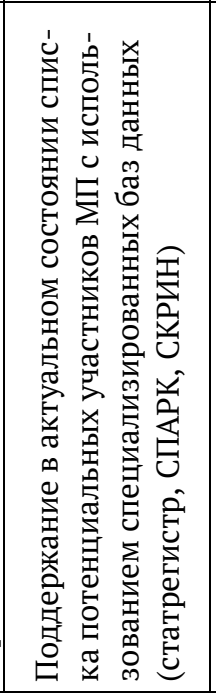 & & & 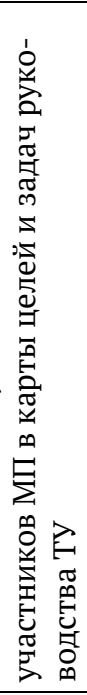 & & 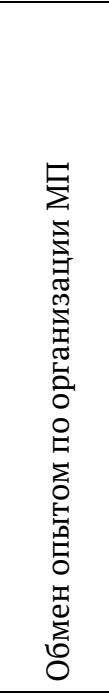 & 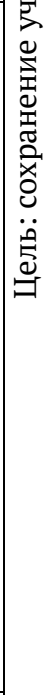 & & 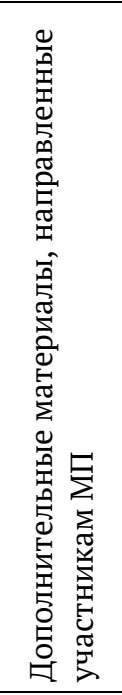 & \\
\hline & - & & & & $N$ & & & & & & & N & \\
\hline & 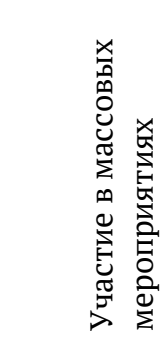 & & & & 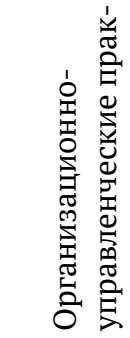 & & & & & & & 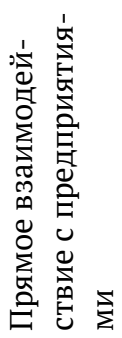 & \\
\hline
\end{tabular}




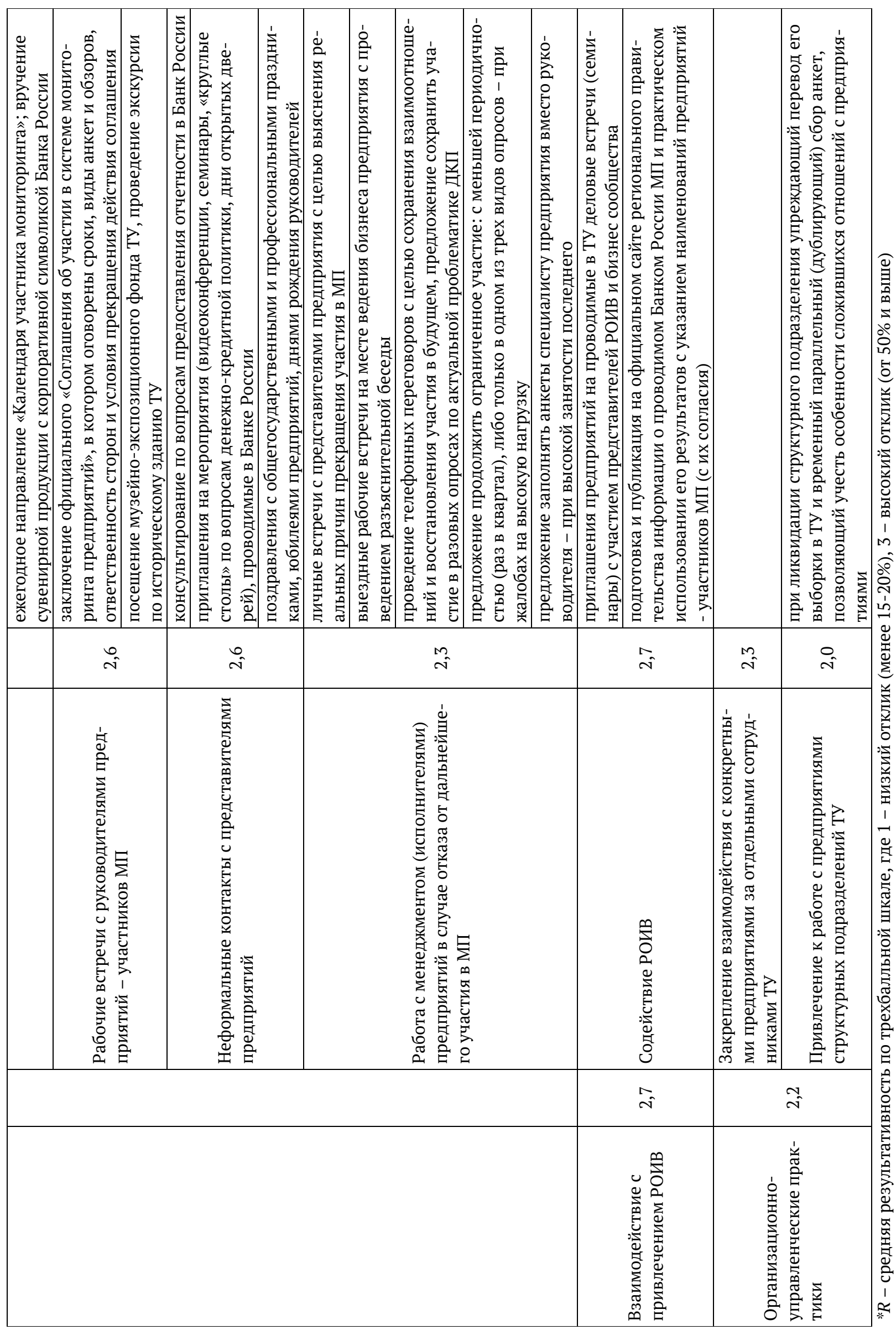

